\title{
ANALYSIS OF INFLUENCE WEDM PARAMETERS ON THE SURFACE FLATNESS DEVIATION DURING MACHINING TOOL STEEL X165CrV12
}

\author{
1'Dorota ONISZCZUK-ŚWIERCZ, 'Rafał ŚWIERCZ, 'Tomasz CHMIELEWSKI, \\ ${ }^{1}$ Tadeusz SAŁACIŃSKI \\ ${ }^{1}$ Warsaw University of Technology, Faculty of Production Engineering, Poland, EU, \\ dorota.swiercz@pw.edu.pl
}

https://doi.org/10.37904/metal.2021.4211

\begin{abstract}
Wire electrical discharge machining (WEDM) is non conventional technology in which the electrical discharges occurring between the wire electrode and workpiece allow to machine difficult to cut material. The shape accuracy of cut high parts is one of the major limitations of WEDM. Establishing favorable machining conditions for the required dimensional accuracy plays a key role in the process. Response surface methodology (RSM) was used to build empirical models on the influence of the discharge energy $E$, workpiece height $H$ and wire tension Fn on the surface flatness deviation $W$ and material removal rate MRR during the machining of tool steel X165CRV12. Developed models can be used in the WEDM process as a guideline for the selection of parameters to achieve the desired surface flatness deviation $W$ and material removal rate $M R R$ in industrial applications.
\end{abstract}

Keywords: WEDM, wire electrical discharge machining, flatness deviation, discharge energy

\section{INTRODUCTION}

Wire electrical discharge machining (WEDM) is precision technology that allows to manufacturing difficult to machining conductive materials. Through the electrical discharges occurring in the gap between the wire and workpiece material is removed [1-2]. Suitable conditions to electrical discharges ensure the dielectric (deionized water) is delivered into the gap. Whit its flow the debris is evacuated from the gap. Dimensional and shape accuracy is one of the most important features characterizing the part after WEDM [3-4]. Predicting favorable machining conditions for the required dimensional and shape accuracy cutting parts plays a key role. Shape errors in cutting material are caused by physical phenomena occurring in the: wire vibrations caused by electric discharges and flowing dielectric as well as uneven distribution of treatment products [5-10]. The dimensional and shape accuracy of the workpieces after machining also depends on the height of the workpiece (along with the height of the cut material, the amount of eroded material facilitating the electric breakdown in the gap increases) [11-15]. The main goal of this research is a better understanding of the relationship between the influence the WEDM process parameters: discharge energy, workpiece heigh and wire tension on the shape errors of cutting parts and material removal rate.

\section{MATERIALS AND METHODS}

Conducted initial research and literature review indicate that the most important parameters of the wire electrical discharge machining which has a strong influence on the material removal mechanism are discharge current and discharge time. These parameters with considering constant discharge voltage $(U)$ represent the discharge energy $(E)$. The dimensional and shape accuracy of the workpieces after machining also depends on the height of the workpiece and wire tension. The preliminary test was conducted to investigate a range of stability discharges for different values of discharge current and pulse time. The measurement of the voltage 
and current waveforms during the electric discharge was done with the probe Tektronix and Pearson current sensor, respectively. The sampling rate was $100 \mathrm{MS} / \mathrm{s}$, 2-Channel registration on the oscilloscope card. Analysis of the obtained data was done in DIAdem. The typical recorded current and voltage waveform during WEDM is shown in (Figure1).

The discharge occurred when the intensity of the voltage field overcame the dielectric resistance in the gap between two electrodes. Open circuit voltage drops to discharge voltage and current increase to discharge current. During discharge time, the material is melted and evaporated as a result of the plasma channel impact. Finally, discharge current and voltage drops to near zero and debris formed as solidified molted materials are through away to the gap. During the time interval, the condition in the gap stabilize, and the process is repeated cyclically. The average discharge energy of the electrical discharge is described in Equation (1):

$E=\int_{0}^{t_{\text {on }}} U_{c}(t) \cdot I_{c}(t) d t \quad(\mathrm{~mJ})$

where: Ic - discharge current, ton - pulse duration time, $U_{c}$ - discharge voltage,

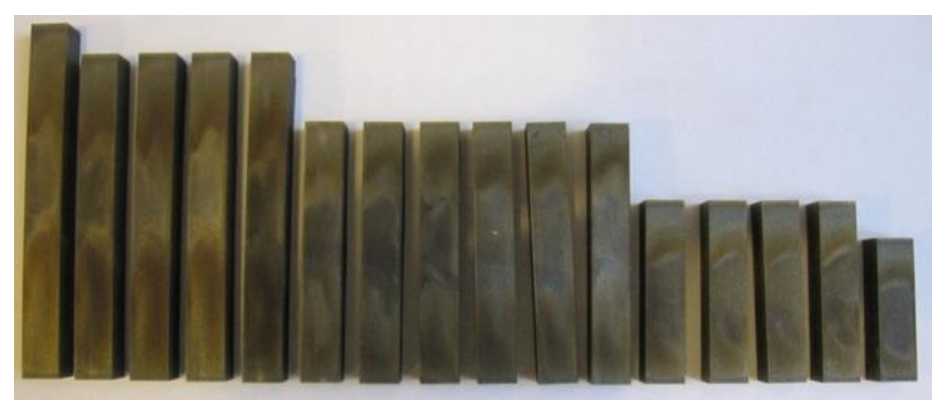

Figure 2 Samples cut after WEDM

The present paper was focused on the analyses of the influence of WEDM parameters and conditions on the flatness deviation of cut parts. Experimental studies were conducted on wire electrical discharge machine Robofil 190 Charmilles. The electrode used was a brass wire with a dimension of $0.25 \mathrm{~mm}$ and deionized water was used as the dielectric. The cutting samples of tool steel X165CRV12 have dimensions of $10 \times 10 \mathrm{x}$ $\mathrm{H} \mathrm{mm}$. The study was conducted according to experimental design, five levels, and three parameters. Experiments were conducted with the following machining conditions: discharge time in the range ton $=1,4-$ $1,8 \mu \mathrm{s}$, workpiece heigh $=40-100 \mathrm{~mm}$, and wire tension $F n=0,4-1,6 \mathrm{daN}$. Discharge voltage was constant $U=30 \mathrm{~V}$. The sixteen samples was cut with different WEDM parameters (Figure 2).

The influence of selected WEDM parameters and condition: discharge pulse, workpiece high and wire tension on surface flatness deviation was investigated. To achieve this goal, experimental research was carried out according to the Hartley design of the experiment, three-level three parameters. Surface flatness deviation measuring was performed on a Carl Zeiss coordinate measuring machine. A measurement strategy was determined in the Calypso software - the head movement path and the number of points were determined (raster strategy, 300 measurement points). Figure $\mathbf{3}$ shows exemplary reports on the performed 
measurements generated in Calypso. For a sample with a height of $100 \mathrm{~mm}$ (maximum cutting height), a clear concave surface was observed in the middle part (Figure 3b). However, in the case of cutting the sample of the smallest height (Figure 3a), no clear shape errors were observed.

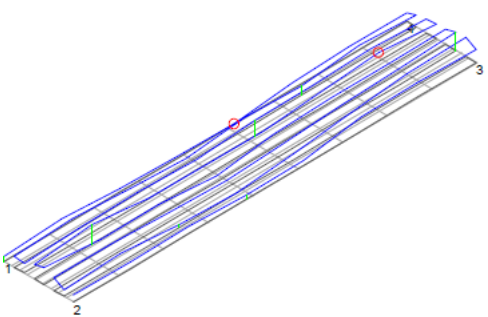

(a)

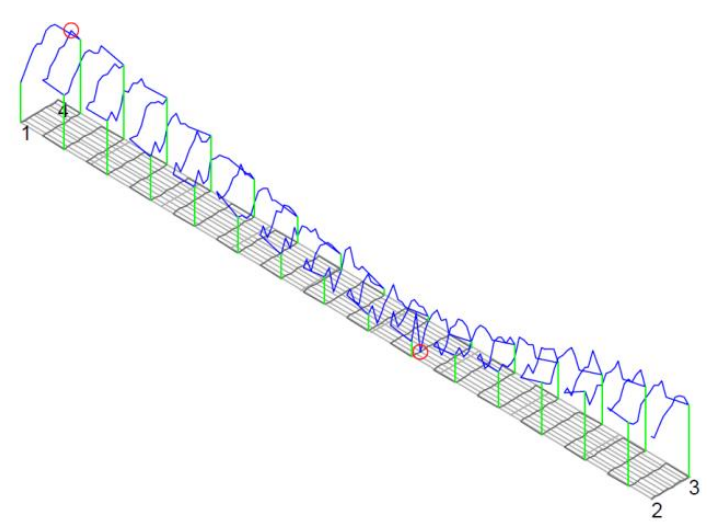

(b)

Figure 3 The graphical presentation of measured flatness deviation on CMM for workpiece height

a) $40 \mathrm{~mm}$, b) $100 \mathrm{~mm}$

\section{RESULTS AND DISCUSSION}

Experimental investigation of the influence of the WEDM process parameters on the surface flatness deviation and MRR was carried out using response surface methodology (RSM). Table 1 shows the levels of machining parameters carried out in the experimental design and observed values of flatness deviation $W$ and material removal rate $M R R$.

Table 1 Design of the experimental matrix

\begin{tabular}{|c|c|c|c|c|c|c|}
\hline \multirow{2}{*}{ No. } & \multicolumn{4}{|c|}{ WEDM paramters } & \multicolumn{2}{|c|}{ Observed values } \\
\hline & $t_{o n}(\mu s)$ & Calculated E (mJ) & $F_{n}(d a N)$ & $H(m m)$ & $W(\mathrm{~mm})$ & $\operatorname{MRR}\left(\mathrm{mm}^{2} / \mathrm{min}\right)$ \\
\hline 1. & 1.5 & 3.37 & 0.64 & 52 & 0.0168 & 55 \\
\hline 2. & 1.5 & 3.37 & 0.64 & 88 & 0.0110 & 54 \\
\hline 3. & 1.5 & 3.37 & 1.36 & 52 & 0.0273 & 37 \\
\hline 4. & 1.5 & 3.37 & 1.36 & 88 & 0.0147 & 38 \\
\hline 5. & 1.7 & 4.21 & 0.64 & 52 & 0.0168 & 65 \\
\hline 6. & 1.7 & 4.21 & 0.64 & 88 & 0.0130 & 65 \\
\hline 7. & 1.7 & 4.21 & 1.36 & 52 & 0.0301 & 54 \\
\hline 8. & 1.7 & 4.21 & 1.36 & 88 & 0.0240 & 55 \\
\hline 9. & 1.4 & 2.83 & 1 & 70 & 0.0168 & 40 \\
\hline 10. & 1.8 & 4.86 & 1 & 70 & 0.0270 & 78 \\
\hline 11. & 1.6 & 3.84 & 0.4 & 70 & 0.0128 & 120 \\
\hline 12. & 1.6 & 3.84 & 1.6 & 70 & 0.0400 & 46 \\
\hline 13. & 1.6 & 3.84 & 1 & 40 & 0.0285 & 54 \\
\hline 14. & 1.6 & 3.84 & 1 & 100 & 0.0151 & 55 \\
\hline 15. & 1.6 & 3.84 & 1 & 70 & 0.0237 & 55 \\
\hline 16. & 1.6 & 3.84 & 1 & 70 & 0.0223 & 56 \\
\hline
\end{tabular}

In the developed regression equations, it was decided to include the average value of the electric discharge energy determined in accordance with equation (1). The pulse energy depends on the pulse time, the current 
and the voltage of the electric discharge. The first two parameters are directly related to each other (the value of the discharge current depends on the pulse time and is a result parameter) for the tested object - a Robofil 190 machine tool generator.

The regression equation was described by the polynomial function of the second degree:

$Y=\beta_{0}+\sum_{i=1}^{k} \beta_{i} X_{i}+\sum_{i=1}^{k} \beta_{i} i X_{i}^{2}+\sum_{i=1, i \neq j}^{k} \beta_{i j} i X_{i} X_{j}+\varepsilon$

The Fisher-Snedecora test $(F)$ was used to verify the significance of the correlation coefficient $R$. The correlation coefficient $R$ was significant when there was a relation for the associated $p$-value $(p=0.05)$. After eliminating the non-significant terms, the final response equations for the surface flatness deviation $W$ and $M R R$ presented in equations 3-4. Table 2 presents the regression summaries for the established equations:

$$
\begin{aligned}
& W=0.0039+0.000087 \cdot E \cdot H-0.0053 \cdot F_{\mathrm{n}}^{2} \\
& M R R=157.85-4.35 \cdot H+18.56 \cdot E+0.026 \cdot H^{2}
\end{aligned}
$$

Table 2 Regression summary

\begin{tabular}{|c|c|c|c|}
\hline $\begin{array}{c}\text { Investigated } \\
\text { parameters }\end{array}$ & ratio $\boldsymbol{R}$ & $\boldsymbol{F} / \boldsymbol{F}_{\text {kr }}$ & $\boldsymbol{p}$-value \\
\hline Flatness deviation W & 0.92 & 9.52 & 0.005 \\
\hline Material removal rate MRR & 0.87 & 3.48 & 0.003 \\
\hline
\end{tabular}

The developed regression equation indicates, that the main parameter influencing the flatness deviation $W$ is the height of the cut material (Figure 4). As the height of the workpiece increases, the error of the surface flatness increases. The obtained value of the flatness deviation is in the range: $0.008-0.05 \mathrm{~mm}$. The largest flatness deviation (about $0.05 \mathrm{~mm}$ ) was obtained for the maximum height of the cut material, the discharge energy and the minimum tension force of the wire (Figure 4a). The conducted experimental studies indicate that the source of shape errors is related to the vibrations of the working electrode caused by many process variables. Along with the growth of the high of cut material, the number of debris increase in the middle of the height in the gap. Local concentration of debris cause an uneven distribution of discharges. Furthermore, this leads to wire vibration. The amplitude of the wire vibration is "reflected" on the workpiece (concave surface areas). The maximum value of the vibration amplitude is in the near central part of the surface.

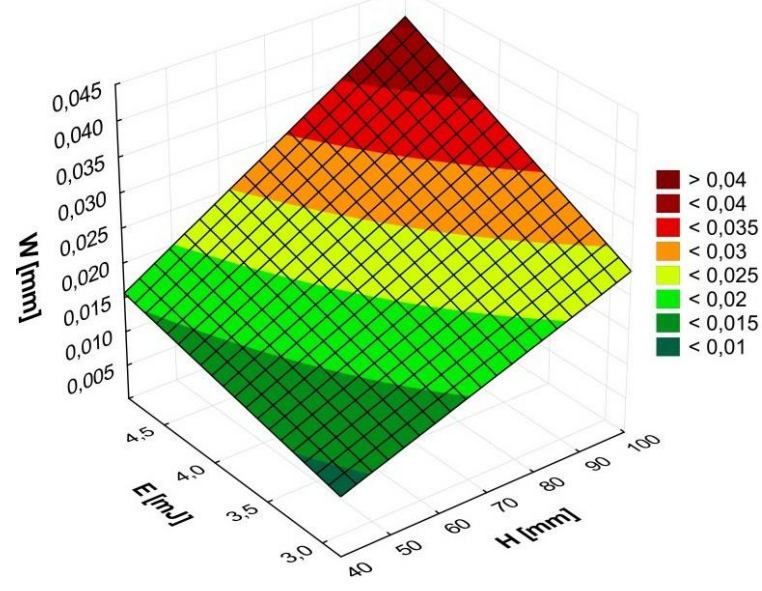

(a)

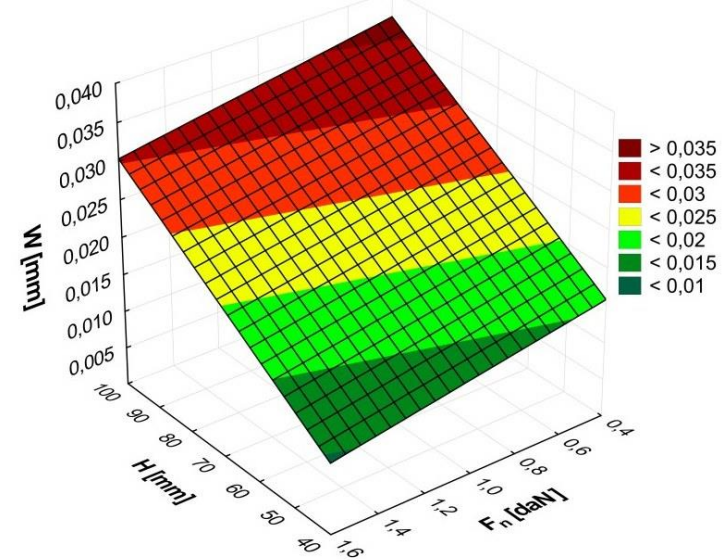

(b)

Figure 4 Estimated response surface plot for the Flatness deviation $W:$ (a) constant wire tension $F n=1$ daN,

(b) constant discharge energy $E=3.84 \mathrm{~mJ}$ 
The value of the material removal rate of the WEDM process depends on the height of the cut material and discharge energy (Figure 5). With the growth of discharge energy the amount of volume of material that is removed from the workpiece during a single discharge grows. This leads directly to an increase in MRR. However, the main factor affecting the MRR is the stability of the EDM process. In the most favorable processing conditions, which are defined by: efficient removal of debris from the gap, uniform discharges on the entire electrode surface as well as the minimum amplitude of wire vibrations, the highest material removal rate is achieved. Depending on the conditions in the gap, the feed rate of the wire is changing. A feed that is too fast in relation to the amount of material removed per unit time will lead to a short circuit and break the electrode. The conducted experimental tests show that with the smallest cutting height $(40 \mathrm{~mm})$ and maximum discharge energy (about $5 \mathrm{~mJ}$ ) it is possible to obtain the $M R R$ equal to $115 \mathrm{~mm}^{2} / \mathrm{min}$.

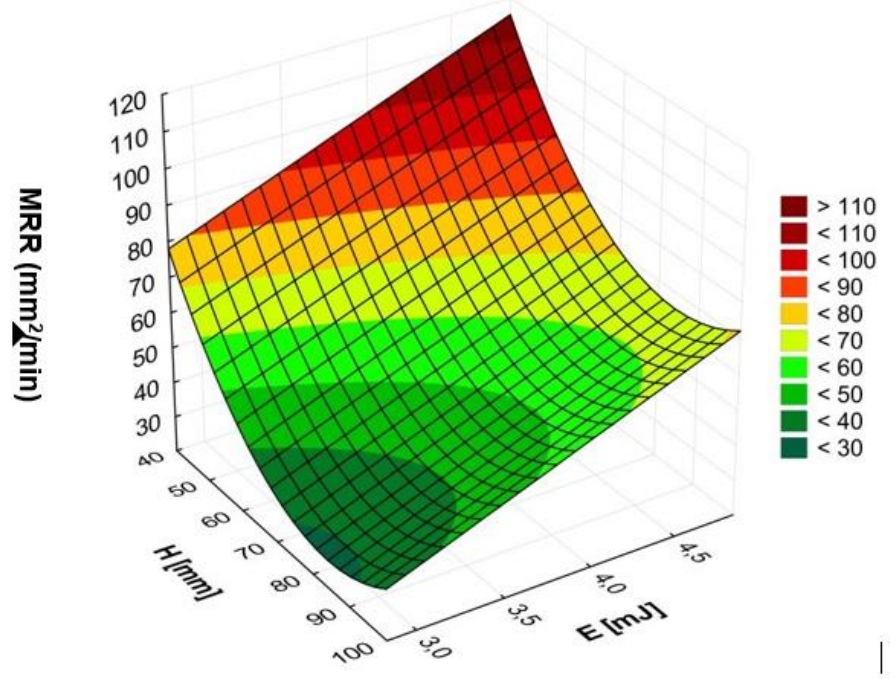

Figure 5 Estimated response surface plot for material removal rate $M R R$

\section{CONCLUSION}

The experimental studies were focused on the analyses of the influence of WEDM parameters on the flatness deviation and material removal rate during machining of tool steel X165CRV12. Summarizing the results of the experimental investigation can be concluded:

- $\quad$ The main process parameter influencing the flatness deviation after WEDM machining in the rough cut is discharge energy and workpiece heigh followed by wire tension. The source of shape errors during WEDM is the wire vibrations that are reflected in the workpiece. The largest flatness deviation (about $0.05 \mathrm{~mm}$ ) was obtained for the maximum: height of the cut material, the discharge energy and the lowest tension force of the wire.

- The developed regression equations could be used in wire electrical discharge machining of tool steel $\mathrm{X} 165 \mathrm{CRV} 12$ as a guideline for the selection of WEDM parameters.

\section{ACKNOWLEDGEMENTS}

This study was conducted with financial support from the Warsaw University of Technology, hereby gratefully acknowledged.

\section{REFERENCES}

[1] STRAKA, L. and DITTRICH, G. Influence of graphite tool electrode shape on TWR and MRR at EDM, MM. Science Journal. 2019, pp. 3479-3485 
[2] ONISZCZUK-ŚWIERCZ, D. and ŚWIERCZ, R. Surface texture after wire electrical discharge machining. In: METAL 2017: Proceedings of 26th International Conference on Metallurgy and Materials. Ostrava: TANGER, 2017, pp. 1400-1406.

[3] MURRAY, J.W.; SUN, J.; PATIL, D.V.; WOOD, T.A.; and CLARE, A.T. Physical and electrical characteristics of EDM debris. Journal of Materials Processing Technology. [online]. 2016, vol. 229, pp. 54-60. Available from: https://doi.org/10.1016/j.jmatprotec.2015.09.019.

[4] KUMAR, R. and SINGH, I. Productivity improvement of micro EDM process by improvised tool. Precision Engineering. [online]. 2018, vol. 51, pp. 529-535, Available from: https://doi.org/10.1016/j.precisioneng.2017.10.008.

[5] XU, B.; GUO, K.; ZHU, L.; WU, X. and LEI, J. Applying Foil Queue Microelectrode with Tapered Structure in Micro-EDM to Eliminate the Step Effect on the 3D Microstructure's Surface. Micromachines [online]. 2020, vol. 11, p. 335, Available from: https://doi.org/10.3390/mi11030335.

[6] BADIDA, M., GOMBAR, M., MASLEJOVA, A., SOBOTOVA, L., KMEC, J. and VAGASKA, A. Evaluation of zinc coating quality by statistical methods. Przemys Chemiczny. 2015, vol. 94, pp. 2146-2149.

[7] STRAKA, L'.; ČORNÝ, I. and PITEL', J. Prediction of the Geometrical Accuracy of the Machined Surface of the Tool Steel EN X30WCrV9-3 after Electrical Discharge Machining with CuZn37 Wire Electrode. Metals. [online]. 2017, vol. 7, no. 462, Available from: https://doi.org/10.3390/met7110462.

[8] WANG, J.; SÁNCHEZ, J.A.; IZQUIERDO, B. and AYESTA, I. Experimental and Numerical Study of Crater Volume in Wire Electrical Discharge Machining. Materials. [online]. 2020, vol. 13, no. 577. Available from: https://doi.org/10.3390/ma13030577.

[9] ŚWIERCZ, R.; ONISZCZUK-ŚWIERCZ and D.; DĄBROWSKI, L. Electrical discharge machining of difficult to cut materials. Archive of Mechanical Engineering. [online]. 2018, vol. 65, pp. 461-476. Available from: https://doi.org/10.24425/ame.2018.125437.

[10] STRAKA, L. And HAŠOVÁ, S. Prediction of the heat-affected zone of tool steel EN X37CrMoV5-1 after diesinking electrical discharge machining. Proceedings of the Institution of Mechanical Engineers, Part B: Journal of Engineering Manufacture. [online]. 2018, vol. 232, pp. 1395-1406, Available from: https://doi.org/10.1177/0954405416667405.

[11] SPADŁO, S. and MŁYNARCZYK, P. Selected Properties of the Micro Electrical Discharge Alloying Process Using Copper Electrode on Aluminum. Transportation Research Procedia. [online]. 2019, vol. 40, pp. 96-101. Available from: https://doi.org/10.1016/j.trpro.2019.07.016.

[12] MŁYNARCZYK, P.; SPADŁO, S. and BARTOS', J. Selected properties of electro-spark deposition on carbon steel using the Alloy 400 electrodes. IOP Conf. Ser.: Mater. Sci. Eng. [online]. 2018, vol. 461, p. 012055. Available from: https://doi.org/10.1088/1757-899X/461/1/012055.

[13] GRIGORIEV, S.N.; KOZOCHKIN, M.P.; PORVATOV, A.N.; VOLOSOVA, M.A. and OKUNKOVA, A.A. Electrical discharge machining of ceramic nanocomposites: sublimation phenomena and adaptive control. Heliyon. [online]. 2019, vol. 5, e02629. Available from: https://doi.org/10.1016/j.heliyon.2019.e02629.

[14] ONISZCZUK-SWIERCZ, D., SWIERCZ, R., CHMIELEWSKI, T. and SALACINSKI, T. Experimental investigation of influence wedm parameters on surface roughness and flatness deviation. METAL 2020 - 29th International Conference on Metallurgy and Materials, Conference Proceedings. Tanger, 2020, pp. 611-617.

[15] KULKARNI, V.N.; GAITONDE, V.N.; KARNIK, S.R.; MANJAIAH, M. and DAVIM, J.P. Machinability Analysis and Optimization in Wire EDM of Medical Grade NiTiNOL Memory Alloy. Materials. [online]. 2020, vol. 13, p. 2184. Available from: https://doi.org/10.3390/ma13092184. 